\title{
Substratos alternativos e métodos de quebra de dormência para produção de mudas de canafístula
}

\author{
Tiago Reis Dutra ${ }^{1}$, Marília Dutra Massad², Mateus Felipe Quintino Sarmento ${ }^{3}$, Jéssica Costa de Oliveira ${ }^{4}$
}

\section{RESUMO}

O objetivo deste estudo foi avaliar o efeito de diferentes métodos de quebra de dormência e o uso do bagaço de cana para composição de substratos alternativos, constituídos a partir da mistura de um substrato comercial, na produção de mudas de canafístula (Peltophorum dubium (Sprengel) Taubert). O experimento foi conduzido em delineamento de blocos casualizados, no esquema fatorial 5 x 4, sendo cinco substratos, Bioplant ${ }^{\circledR} ; 75 \%$ Bioplant $^{\circledR}+25 \%$ Bagaço de cana $(75 \mathrm{~B}+25 \mathrm{BC}) ; 50 \%$ Bioplant $^{\circledR}+50 \%$ Bagaço de cana $(50 \mathrm{~B}+50 \mathrm{BC}) ; 25 \%$ Bioplant $^{\circledR}+75 \%$ Bagaço de cana $(25 \mathrm{~B}+75 \mathrm{BC})$; Bagaço de cana (100\%), e quatro métodos de quebra de dormência (testemunha, escarificação com o uso de lixa, imersão em água quente e escarificação com ácido sulfúrico) com três repetições. Foram avaliados o índice de velocidade de emergência (IVE); o tempo médio de emergência (TME); a percentagem de germinação; a altura da parte aérea; o diâmetro do coleto; a massa seca da parte aérea; a massa seca de raiz; a massa seca total; a relação altura da parte aérea/diâmetro do coleto; a relação altura da parte aérea/massa seca da parte aérea; o índice de qualidade de Dickson; a taxa de crescimento absoluto e a taxa de crescimento relativo. Os tratamentos de imersão em água quente e de escarificação com ácido sulfúrico foram responsáveis pelos maiores percentuais de emergência e IVE, além dos de menor TME. O uso do bagaço de cana mostrou-se tecnicamente viável na composição dos substratos $75 \mathrm{~B}+25 \mathrm{BC}$ e 50B $+50 \mathrm{BC}$, que, juntamente ao Bioplant ${ }^{\circledR}$, proporcionaram as maiores taxas de crescimento e os maiores índices de qualidade das mudas de canafístula.

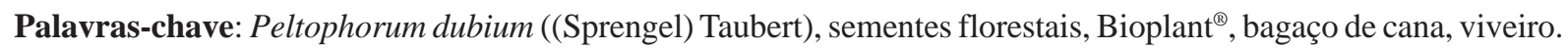

\section{ABSTRACT}

\section{Alternative substrates and methods of breaking dormancy for the production of canafístula seedlings}

This study aimed to evaluate the effect of different methods to break dormancy and the use of sugarcane bagasse in the composition of alternative substrates made from a mixture of commercial substrate, in canafistula (Peltophorum dubium (Sprengel) Taubert) seedling production The experiment was carried out in randomized blocks in a $4 \mathrm{x} 5$ factorial design, with five substrates, Bioplant ${ }^{\circledR} ; 75 \%$ Bioplant $^{\circledR}+25 \%$ sugarcane bagasse $(75 \mathrm{~B}+25 \mathrm{BC}) ; 50 \%$ Bioplant $^{\circledR}+50 \%$ sugarcane bagasse $(50 \mathrm{~B}+50 \mathrm{BC}) ; 25 \%$ Bioplant $^{\circledR}+75 \%$ sugarcane bagasse $(25 \mathrm{~B}+75 \mathrm{BC})$, sugar cane bagasse $(100 \%)$ and four methods of breaking dormancy (control, scarification with sandpaper, immersion in hot water and scarification with sulfuric acid) with three replications. The emergence index (IVE), mean emergence time (TME), emergence percentage,

Recebido para publicação em 08/07/2011 e aprovado em 11/12/2012.

${ }^{1}$ Engenheiro Florestal, Mestre. Instituto Federal de Educação, Ciência e Tecnologia do Norte de Minas Gerais, Campus Salinas, Fazenda Varginha, Km 02, Rodovia Salinas/ Taiobeiras, 39560-000, Salinas, Minas Gerais, Brasil. tiagoreisdutra@gmail.com (autor para correspondência),

${ }^{2}$ Engenheira-Agrônoma, Mestre. Instituto Federal de Educação, Ciência e Tecnologia do Paraná, Campus Irati, Pedro Koppe, 100, Vila Matilde, 84500-000, Irati, Paraná, Brasil. mariliamassad@yahoo.com.br

${ }^{3}$ Graduando em Engenharia Florestal. Instituto Federal de Educação, Ciência e Tecnologia do Norte de Minas Gerais, Campus Salinas, Fazenda Varginha, Km 02, Rodovia Salinas/ Taiobeiras, 39560-000, Salinas, Minas Gerais, Brasil. mateusengflorestal@hotmail.com

${ }^{4}$ Graduando em Engenharia Florestal. Instituto Federal de Educação, Ciência e Tecnologia do Norte de Minas Gerais, Campus Salinas, Fazenda Varginha, Km 02, Rodovia Salinas/ Taiobeiras, 39560-000, Salinas, Minas Gerais, Brasil. jessicataiocosta2010@ hotmail.com 
shoot height, diameter of the collar; shoot dry weight, root dry weight, total dry weight, the shoot height:diameter of the colla ratio and shoot height:shoot dry weight ratio; Dickson quality index, absolute growth rate and relative growth rate. The treatments of immersion in hot water and sulfuric acid scarification were responsible for the highest percentages of emergence and IVE, and the lowest TME. The use of sugarcane bagasse proved to be technically feasible in the composition of substrates $75 \mathrm{~B}+25 \mathrm{BC}$ and $50 \mathrm{~B}+50 \mathrm{BC}$, where they, along with the Bioplant ${ }^{\circledR}$, provided the highest growth rates and quality score for canafistula seedlings.

Key words: Peltophorum dubium ((Sprengel) Taubert), forest seeds, Bioplant ${ }^{\circledR}$, sugar cane bagasse, nursery.

\section{INTRODUÇÃO}

A canafístula (Peltophorum dubium (Sprengel) Taubert), popularmente conhecida na região norte de Minas Gerais como "acari”, apresenta grande distribuição natural, desde a Bahia, Rio de Janeiro, Minas Gerais, Mato Grosso do Sul, até o Paraná (Lorenzi, 2002).

Sua árvore é muito utilizada na arborização urbana, na construção civil e no reflorestamento misto de áreas degradadas. Além de proporcionar ótima sombra, quando isolada, apresenta grande porte, alcançando de 15 a 40 metros de altura e rápido crescimento (Piroli et al., 2005; Alves et al., 2011).

A crescente expansão dos projetos de restauração florestal tem aumentado a demanda por espécies nativas, tornando-se cada vez mais necessários estudos que visem à produção de mudas com menores custos e com qualidade elevada.

A dormência das sementes e a composição do substrato são dois dos vários fatores que exercem influência no desenvolvimento de mudas, durante a fase de viveiro.

A dormência de sementes representa recurso eficaz para a perpetuação das espécies, conferindo à semente resistência às condições desfavoráveis do ambiente e distribuindo a germinação no tempo (Brancalion et al., 2011). Entretanto é, geralmente, uma característica indesejável para os viveiristas, gerando problemas como desuniformidade entre as mudas, além de maior tempo de exposição às condições adversas, como a ação de insetos e doenças, e maior risco de perda de sementes por deterioração (Azeredo et al., 2010).

Para a produção de mudas de canafístula, é necessária a quebra da dormência natural de suas sementes, ocasionada pela impermeabilidade de seu tegumento. Adormência tegumentar é muito frequente entre as espécies florestais, caracterizando-se pela dificuldade de absorção de água pela semente, o que a impede de iniciar a hidratação e, consequentemente, restringe as reações metabólicas básicas da germinação (Azeredo et al., 2010; Vasconcelos et al., 2010). Entre os tratamentos de quebra de dormência utilizados, com sucesso, para superação da dormência tegumentar de espécies florestais, destacam-se as escarificações mecânica e química, além da imersão das sementes em água quente (Oliveira et al., 2003). Esses métodos baseiam-se no princípio de dissolver a camada cuticular cerosa, ou formar estrias ou perfurações no tegumento das sementes, o que propicia o início mais rápido e uniforme do processo germinativo (Scalon et al., 2005).

Além do tratamento pré-germinativo, o tipo de substrato influencia tanto a germinação das sementes, quanto o crescimento das mudas. Segundo Martins et al. (2008), substrato é o suporte físico no qual a semente é colocada e tem como função manter as condições adequadas de fornecimento de água, oxigênio e nutrientes, para sua germinação e posterior desenvolvimento das mudas. Inúmeros substratos, em sua constituição original, ou combinados, são usados atualmente para propagação de espécies florestais (Simões et al., 2012), devendo-se observar, no momento da escolha, além de suas características físicas e químicas, os aspectos econômicos, quais sejam: baixo custo e grande disponibilidade (Dutra et al., 2012).

O desenvolvimento da consciência ambiental e a busca por alternativas econômica e tecnicamente viáveis vêm tornando o reaproveitamento de resíduos e o uso de compostos orgânicos alvo de pesquisas, para incorporação desses insumos na composição dos substratos. Dentre os resíduos com potencial de utilização, destaca-se o bagaço de cana.

A utilização do bagaço de cana na composição de substrato para produção de mudas, na região de SalinasMG, constitui-se em alternativa barata e de fácil disponibilidade, já que a cana-de-açúcar é matéria prima para o principal e o mais conhecido produto da região, a cachaça artesanal.

Em geral, esse resíduo apresenta adequada composição química, capaz de proporcionar bom desenvolvimento às plantas (Cunha et al., 2005), além de sua utilização contribuir para a diminuição do seu acúmulo no meio ambiente.

O uso de substrato que contém, em sua mistura, o bagaço tem sido realizado com êxito para produção de 
mudas de eucalipto (Freitas et al., 2006) e citros (Serrano et al., 2004), conferindo a essas mudas qualidades morfofisiológicas semelhantes ou superiores às alcançadas com o uso de substratos comerciais.

Diante do exposto, objetivou-se, com este trabalho, avaliar o efeito de diferentes métodos de quebra de dormência e o uso do bagaço de cana para composição de substratos alternativos, constituídos a partir da mistura de um substrato comercial, na produção de mudas de canafístula.

\section{MATERIAL E MÉTODOS}

As sementes de canafístula (Peltophorum dubium) foram coletadas de sete matrizes localizadas no Instituto Federal do Norte de Minas Gerais - (IFNMG / Campus Salinas) (22¹3'16" S e 5448'2" O), município de SalinasMG, em outubro de 2010.

O experimento foi realizado durante os meses de novembro de 2010 a fevereiro de 2011, no Setor de Agricultura I, do IFNMG - Câmpus Salinas, em delineamento de blocos casualizados, com três repetições, no esquema fatorial ( $5 \mathrm{x}$ 4), sendo avaliados cinco tipos de substratos e quatro métodos para quebra de dormência das sementes. A unidade experimental foi constituída por 12 sementes.

Os substratos avaliados foram: Bioplant ${ }^{\circledR} ; 75 \%$ Bioplant $^{\circledR}+25 \%$ Bagaço de Cana $(75 \mathrm{~B}+25 \mathrm{BC}) ; 50 \%$ Bioplant $^{\circledR}+50 \%$ Bagaço de Cana $(50 \mathrm{~B}+50 \mathrm{BC}) ; 25 \%$ Bioplant ${ }^{\circledR}+75 \%$ Bagaço de Cana $(25 \mathrm{~B}+75 \mathrm{BC})$; Bagaço de Cana (100\%).

A caracterização química dos substratos foi realizada pelo Laboratório de Fertilidade do Solo da UFVJM. As características físicas de porosidade total, macroporosidade, microporosidade e capacidade máxima de retenção de água dos substratos, foram determinadas por metodologia proposta por Carvalho \& Silva (1992) citado por Dutra et al. (2012) (Tabela 1).

Foram aplicados os seguintes tratamentos às sementes: Testemunha (sementes sem tratamento para quebra de dormência); Escarificação mecânica (Lixa n ${ }^{\circ}$ 60): as sementes foram lixadas superficialmente na região oposta ao eixo embrionário e imersas em água, por 24 horas, à temperatura de $25^{\circ} \mathrm{C}$; Imersão em água quente: as sementes foram imersas em água quente $\left(95^{\circ} \mathrm{C}\right)$ e deixadas em repouso fora do aquecimento, por 24 horas, à temperatura de $25^{\circ} \mathrm{C}$; Escarificação química: as sementes foram submersas em ácido sulfúrico concentrado (98\%) por 15 minutos e, em seguida, lavadas em água corrente.

Após a realização dos tratamentos para quebra de dormência, as sementes foram desinfestadas em solução de hipoclorito de sódio ( $2 \%$ ) por 3 minutos, posteriormente, foram semeadas em tubetes com capacidade volumétrica de $55 \mathrm{~cm}^{3}$, preenchidos com os diferentes ti- pos de substratos, sendo mantidos sob irrigação por microaspersores bailarina, com vazão de $85 \mathrm{~L} \mathrm{~h}^{-1}$ em viveiro telado, coberto com sombrite de $50 \%$. As temperatura e umidade relativa do ar, médias, durante o período experimental foram, respectivamente, $29,7^{\circ} \mathrm{C}$ e $52,3 \%$.

O número de sementes emergidas foi avaliado diariamente, sempre no mesmo horário, adotando-se como critério a emergência dos cotilédones, com o consequente surgimento do hipocótilo. Aos 28 dias após a semeadura (DAS), foram avaliados os seguintes parâmetros: Emergência - percentagem de sementes que emergiram; Índice de velocidade de emergência (IVE) - determinado de acordo com a metodologia de Maguire (1962), descrita por Carvalho \& Carvalho (2009); Tempo médio de emergência (TME) - de acordo com a metodologia de Laboriau (1983), descrita por Carvalho \& Carvalho (2009), com o resultado expresso em dias após a semeadura.

A partir do $30^{\circ} \mathrm{DAS}$, as mudas receberam fertirrigação quinzenal, com $6 \mathrm{~mL}$ planta $^{-1}$ de solução aquosa, contendo $4 \mathrm{~g} \mathrm{~L}^{-1}$ de sulfato de amônio, $10 \mathrm{~g} \mathrm{~L}^{-1}$ de superfosfato simples, $4 \mathrm{~g} \mathrm{~L}^{-1}$ de cloreto de potássio e $1 \mathrm{~g} \mathrm{~L}^{-1}$ de FTE BR12 (9\% Zn, 3\% Fe, 2\% Mn, 0,1\% Mo, 1,8\% B, 0,8\% Cu).

Aos 100 DAS, foram avaliados a altura da parte aérea $(\mathrm{H} ; \mathrm{cm})$, com uma régua, bem como o diâmetro do coleto das plantas (DC; mm), com paquímetro. Em seguida, as plantas foram colhidas e separadas em parte aérea e raízes, lavadas em água corrente e secadas em estufa com circulação forçada de ar, a aproximadamente $65^{\circ} \mathrm{C}$, até peso constante. Avaliaram-se massa seca da parte aérea (MSPA; g planta ${ }^{-1}$ ) e massa seca de raízes (MSR; g planta $\left.^{-1}\right)$, a partir das quais foi determinada a massa seca total (MST; g planta ${ }^{-1}$ ). Esses parâmetros foram transformados em índices de qualidade de mudas, conforme sugerido por Gomes et al. (2002): H/DC, H/MSPA, MSPA/ MSR, e no Índice de Qualidade de Dickson - IQD (Dickson et al., 1960), calculado por:

$$
I Q D=\frac{M S T(g)}{[H(\mathrm{~cm}) / D C(m m)]+[M S P A(g) / M S R(g)]}
$$

Também foram calculadas as taxas de crescimento absoluto e de crescimento relativo, conforme metodologia proposta por Hunt (1982):

$T C A=\frac{P 2-P 1}{t 2-t 1}$

$T C R=\frac{\operatorname{Ln} P 2-\operatorname{Ln} P 1}{t 2-t 1}$

em que: TCA $=$ taxa de crescimento absoluto $\left(\mathrm{g} \mathrm{dia}^{-1}\right)$, TCR $=$ taxa de crescimento relativo $\left(\mathrm{g} \mathrm{g}^{-1} \mathrm{dia}^{-1}\right)$, P é o peso total da matéria seca da planta e $\mathrm{t}=$ tempo, com índice $1=$ valor inicial (28 DAS) e índice $2=$ valor final (100 DAS).

Os dados obtidos foram submetidos à análise de variância e, quando o efeito do tratamento pré-emergên- 
cia, ou do tipo de substrato, foi significativo, as médias foram comparadas pelo teste de Tukey $(\mathrm{p}<0,05)$. Todas as análises estatísticas foram realizadas utilizando-se o software Statistica 8.0 (StatSoft, 2007).

\section{RESULTADOS E DISCUSSÃO}

Não houve efeito significativo da interação entre os métodos de quebra de dormência e os tipos de substratos, para nenhuma das características avaliadas, ocorrendo somente o efeito isolado desses fatores (Tabela 2).

Os tratamentos de pré-emergência influenciaram o índice de velocidade de emergência (IVE), o tempo médio de emergência (TME) e a percentagem de emergência (E) (Tabela 2).

Nota-se que as sementes submetidas aos tratamentos de imersão em água quente e de escarificação química com ácido sulfúrico apresentaram médias de IVE (16,60 e 17,42 , respectivamente) e E $(95,5$ e $98,9 \%$, respectivamente) superiores às da testemunha $(3,25$ e $22,4 \%)$; as submetidas à escarificação com lixa, médias 10,23 e 61,7\% (Tabela 3). Os mais altos teores de água alcançados pelas sementes, nos dois tratamentos (Imersão em água quente: 69,8\% ; Escarificação com ácido sulfúrico: 72,3\%), em comparação aos demais (Testemunha: 9,82\%; Lixa: 67,9\%), podem ter contribuído de forma direta para a superioridade dos valores de IVE e percentagem de emergência.

O maior índice de velocidade de emergência das plântulas, proporcionados por esses métodos de quebra de dormência, é de grande importância, haja vista que maiores valores de IVE poderão resultar na formação de mudas em menor tempo e, consequentemente, menor necessidade de permanência no viveiro. Resultado semelhante foi observado por Oliveira et al. (2003), avaliando diferentes métodos de quebra de dormência, para a mesma espécie em estudo; entretanto, os valores da velocidade de emergência, obtidos por esses autores, são inferiores aos observados neste trabalho. A eficiência dos dois métodos em promover mais rápida emergência também foi observada em outras espécies, como a Leucaena leucocephala (Oliveira \& Medeiros Filho, 2007) e a Apeiba tibourbou (Pacheco \& Matos, 2009).

O menor IVE $(3,25)$, nas sementes sem tratamento prégerminativo (Testemunha), resultou em maior TME (Tabela 3). Esses resultados confirmam a ocorrência de dormência tegumentar nas sementes de canafístula, pois seu percentual de germinação, ao final dos 28 dias, foi de apenas 22,4\% (Tabela 3), índice 3,8 vezes menor que o da média dos demais tratamentos.

Outros autores que trabalharam com sementes de canafístula também recomendaram, para melhor germinação, os tratamentos de imersão em água quente (Salerno et al., 1996; Oliveira et al., 2003) e de escarificação química com ácido sulfúrico (Piroli et al., 2005).

A altura da parte aérea $(\mathrm{H})$, o diâmetro do coleto (DC), a massa seca da parte aérea (MSPA), a massa seca de raiz (MSR), a massa seca total (MST), os índices H/MSPA e IQD, além das taxas de crescimento absoluto (TCA) e relativo (TCR) foram influenciados pelos tipos de substratos

Tabela 1. Características químicas e físicas dos substratos utilizados na produção de mudas de canafístula

\begin{tabular}{|c|c|c|c|c|c|}
\hline \multirow{2}{*}{ Características $^{1}$} & \multicolumn{5}{|c|}{ Substrato $^{2}$} \\
\hline & Bioplant $^{\circledast}$ & $75 B+25 B C$ & $50 \mathrm{~B}+50 \mathrm{BC}$ & $25 \mathrm{~B}+75 \mathrm{BC}$ & Bagaço de Cana \\
\hline$\overline{\mathrm{pH}}$, água & 5,0 & 5,1 & 5,3 & 5,3 & 5,5 \\
\hline M.O, dag kg-1 & 20,5 & 7,7 & 7,3 & 7,3 & 6,3 \\
\hline $\mathrm{P}, \mathrm{mg} \mathrm{dm}^{-3}$ & 776,48 & 535,99 & 400,47 & 244,56 & 7,30 \\
\hline $\mathrm{K}, \mathrm{mg} \mathrm{dm}^{-3}$ & 1.410 & 843,6 & 630,8 & 486,4 & 60,8 \\
\hline $\mathrm{Ca}, \mathrm{cmol}_{\mathrm{c}} \mathrm{d} \mathrm{m}^{-3}$ & 12,22 & 7,52 & 4,82 & 3,44 & 0,40 \\
\hline $\mathrm{Mg}, \mathrm{cmol}_{\mathrm{c}} \mathrm{d} \mathrm{m}^{-3}$ & 4,72 & 3,34 & 2,92 & 2,28 & 0,24 \\
\hline $\mathrm{Al}, \mathrm{cmol}_{\mathrm{c}} \mathrm{c}^{\mathrm{c}} \mathrm{m}^{-3}$ & 0,17 & 0,17 & 0,13 & 0,15 & 0,17 \\
\hline $\mathrm{H}+\mathrm{Al}, \mathrm{cmol}_{\mathrm{c}} \mathrm{d} \mathrm{m}^{-3}$ & 8,1 & 5,80 & 3,70 & 4,20 & 1,50 \\
\hline $\mathrm{t}, \mathrm{cmol}_{\mathrm{c}} \mathrm{d} \mathrm{m}^{\mathrm{c}}$ & 20,73 & 13,02 & 9,36 & 6,97 & 0,80 \\
\hline $\mathrm{T}, \mathrm{cmol}_{\mathrm{c}} \mathrm{d} \mathrm{m}^{-3}$ & 28,66 & 13,19 & 9,49 & 7,12 & 0,97 \\
\hline $\mathrm{SB}, \mathrm{cmol}_{\mathrm{c}} \mathrm{d} \mathrm{m}^{-3}$ & 20,56 & 18,82 & 13,06 & 11,17 & 2,30 \\
\hline $\mathrm{m}, \%$ & 1,0 & 1 & 1 & 2 & 18 \\
\hline $\mathrm{V}, \%$ & 72 & 69 & 72 & 62 & 35 \\
\hline Porosidade Total, \% & 62,57 & 61,58 & 54,21 & 44,48 & 25,38 \\
\hline Macroporosidade, $\%$ & 19,57 & 22,48 & 23,13 & 21,31 & 12,77 \\
\hline Microporosidade, $\%$ & 43,01 & 39,10 & 31,08 & 23,17 & 12,61 \\
\hline CMRA, mL $55 \mathrm{~cm}^{-3}$ & 23,65 & 21,50 & 17,10 & 12,74 & 6,93 \\
\hline
\end{tabular}

${ }^{1}$ M.O. = matéria orgânica; $\mathrm{t}=$ capacidade efetiva de troca de cátions; $\mathrm{T}=$ capacidade de troca de cátions; $\mathrm{SB}=$ soma de bases; $\mathrm{m}=$ saturação por alumínio; $\mathrm{V}=$ saturação por bases; $\mathrm{CMRA}=$ Capacidade máxima de retenção de água. ${ }^{2} \mathrm{~B}=\%$ de $\mathrm{Bioplant}{ }^{\circledR}$; vermiculita; $\mathrm{BC}=\%$ de Bagaço de Cana. 
Tabela 2. Resumo das análises de variância das variáveis avaliadas nas mudas de canafístula (Peltophorum dubium) aos 100 dias após semeadura $^{1}$

\begin{tabular}{lccccc}
\hline & Bloco & Substrato $(\mathbf{S})$ & Dormência $(\mathbf{D})$ & $\mathbf{S} \mathbf{x} \mathbf{D}$ & Resíduo \\
\cline { 2 - 5 } GL & $\mathbf{2}$ & $\mathbf{4}$ & $\mathbf{3}$ & $\mathbf{1 2}$ & $\mathbf{3 8}$ \\
\cline { 2 - 6 } & & & Quadrados médios & \\
\hline IVE & $0,67^{\text {n.s }}$ & $2,41^{\text {n.s }}$ & $588,3^{*}$ & $3,61^{\text {n.s }}$ & 6,97 \\
TME & $2,20^{\text {n.s }}$ & $0,51^{\text {n.s }}$ & $1041,5^{*}$ & $1,43^{\text {n.s }}$ & 1,87 \\
E & $143,9^{\text {n.s }}$ & $363,6^{\text {n.s }}$ & $17425,3^{*}$ & $132,0^{\text {n.s }}$ & 217,1 \\
Altura & $84,69^{\text {n.s }}$ & $53,25^{*}$ & $2,52^{\text {n.s }}$ & $1,38^{\text {n.s }}$ & 5,12 \\
Diâmetro & $4,93^{\text {n.s }}$ & $3,86^{*}$ & $0,18^{\text {n.s }}$ & $0,03^{\text {n.s }}$ & 0,32 \\
MSPA & $3,20^{\text {n.s }}$ & $1,87^{*}$ & $0,004^{\text {n.s }}$ & $0,04^{\text {n.s }}$ & 0,17 \\
MSR & $0,73^{\text {n.s }}$ & $0,20^{*}$ & $0,001^{\text {n.s }}$ & $0,005^{\text {n.s }}$ & 0,022 \\
MST & $6,99^{\text {n.s }}$ & $3,29^{*}$ & $0,004^{\text {n.s }}$ & $0,06^{\text {n.s }}$ & 0,308 \\
H/DC & $0,28^{\text {n.s }}$ & $0,21^{\text {n.s }}$ & $0,16^{\text {n.s }}$ & $0,17^{\text {n.s }}$ & 0,303 \\
H/MSPA & $1,84^{\text {n.s }}$ & $1,82^{*}$ & $0,32^{\text {n.s }}$ & $0,44^{\text {n.s }}$ & 0,54 \\
MSR/MSPA & $0,005^{\text {n.s }}$ & $0,037^{\text {n.s }}$ & $0,012^{\text {n.s }}$ & $0,022^{\text {n.s }}$ & 0,018 \\
IQD & $0,183^{\text {n.s }}$ & $0,068^{* *}$ & $0,0005^{\text {n.s }}$ & $0,001^{\text {n.s }}$ & 0,006 \\
TCA & $0,001^{\text {n.s }}$ & $0,0006^{*}$ & $0,000002^{\text {n.s }}$ & $0,00001^{\text {n.s }}$ & 0,00006 \\
TCR & $0,0003^{\text {n.s }}$ & $0,0003^{*}$ & $0,0006^{\text {n.s }}$ & $0,00002^{\text {n.s }}$ & 0,00004 \\
\hline
\end{tabular}

* significativo a $\mathrm{p}<0,05 ; \mathrm{n} . \mathrm{s}$ - não significativo a $\mathrm{p}<0,05$. Índice de velocidade de emergência (IVE); Tempo médio de emergência (TME); Percentagem de emergência (E); Massa seca da parte aérea (MSPA); Massa seca de raiz (MSR); Massa seca total (MST); Relação altura da parte aérea diâmetro do coleto (H/DC); Relação altura da parte aérea massa seca da parte aérea (H/MSPA); Índice de qualidade de Dickson (IQD); Taxa de crescimento absoluto (TCA) e Taxa de crescimento relativo (TCR).

(Tabela 2). Nota-se que, em boa parte, essas variáveis, avaliadas nos substratos 75B+25BC e 50B+50BC, apresentaram valores superiores, igualando-se aos observados no Bioplant ${ }^{\circledR}$ (Figura 1), demonstrando grande potencial do uso do bagaço de cana na composição de substratos para produção de mudas de canafístula, proporcionando redução nos custos de produção, além dos ganhos ambientais pelo reaproveitamento desse resíduo.

Tanto a altura como o diâmetro são parâmetros de fácil mensuração, amplamente utilizados como indicador de qualidade das mudas (Gomes et al., 2003), sendo de boa aceitação técnica, oferecendo excelente estimativa da predição do crescimento inicial no campo.

Os substratos Bioplant ${ }^{\circledR}, 75 \mathrm{~B}+25 \mathrm{BC}, 50 \mathrm{~B}+50 \mathrm{BC}$ e $25 \mathrm{~B}+75 \mathrm{BC}$ proporcionaram os maiores valores da altura da parte aérea das plantas $(\mathrm{H})$, atingindo $\mathrm{H}$ máxima de 13,$8 ; 13,5 ; 12,8$ e 11,2 cm, respectivamente (Figura 1a). O bom crescimento em altura de mudas de espécies florestais, utilizando substratos compostos por resíduos orgânicos, também foi obtido por Muniz et al. (2007).

Assim como observado para altura da parte aérea $(\mathrm{H})$, as mudas cultivadas em Bioplant ${ }^{\circledR}(3,55 \mathrm{~mm}), 75 \mathrm{~B}+25 \mathrm{BC}$ $(3,33 \mathrm{~mm})$ e $50 \mathrm{~B}+50 \mathrm{BC}(3,36 \mathrm{~mm})$ apresentaram os maiores valores de diâmetro do coleto das plantas (DC) (Figura 1b). Segundo Souza et al. (2006), essas mudas apresentariam maiores percentuais de sobrevivência no campo, pois plantas de DC superiores possuem maior capacidade de formação e de crescimento de novas raízes.

As características químicas mais elevadas dos substratos Bioplant $^{\circledR}, 75 \mathrm{~B}+25 \mathrm{BC}$ e 50B $+50 \mathrm{BC}$, como os te- ores de Pe K (Tabela 1), podem ter contribuído para a maior produção de massa seca da parte aérea (MSPA) $(1,363$; 1,280; e 1,251 $\mathrm{g} \mathrm{planta}^{-1}$, respectivamente), massa seca de raízes (MSR) $\left(0,512 ; 0,485\right.$ e 0,437 g planta $^{-1}$, respectivamente) e massa seca total (MST) $(1,875 ; 1,764$ e 1,688 g planta $^{-1}$, respectivamente) das mudas de canafístulas (Figuras 1c, 1d e 1e). Resultados similares com o uso do bagaço de cana foram observados na produção de massa seca da parte aérea e do sistema radicular (Freitas et al., 2006) de mudas de eucalipto e na MSPA de mudas de maracujazeiroamarelo (Serrano et al., 2006). O substrato 50B+50BC apresentou valores superiores em variáveis de grande relevância na produção de mudas, possibilitando uma redução no uso de $50 \%$ do substrato comercial e, consequentemente, reduzindo os custos de produção.

Esses substratos também apresentaram características físicas superiores às dos demais (Tabela 1). Os mais

Tabela 3. Índice de velocidade de emergência (IVE), tempo médio de emergência (TME) e percentagem de emergência (E) de mudas de canafístula, submetidas a diferentes tratamentos prégerminativos $^{1}$

\begin{tabular}{lrcc}
\hline \multirow{2}{*}{ Tratamentos } & \multicolumn{3}{c}{ Variáveis } \\
\cline { 2 - 4 } & \multicolumn{1}{c}{ IVE } & TME (dias) & $\mathbf{E ( \% )}$ \\
\hline Testemunha & $3,25 \mathrm{c}$ & $26,2 \mathrm{a}$ & $22,4 \mathrm{c}$ \\
Escarificação (Lixa) & $10,23 \mathrm{~b}$ & $11,1 \mathrm{~b}$ & $61,7 \mathrm{~b}$ \\
Imersão em água quente & $16,60 \mathrm{a}$ & $11,3 \mathrm{~b}$ & $95,5 \mathrm{a}$ \\
Ácido sulfúrico (98\%) & $17,42 \mathrm{a}$ & $11,8 \mathrm{~b}$ & $98,9 \mathrm{a}$ \\
\hline
\end{tabular}

Médias seguidas da mesma letra na coluna não diferem entre si pelo teste Tukey a $5 \%$ de probabilidade. 
elevados valores de CMRA proporcionaram melhor suprimento de água para a germinação das sementes e posterior desenvolvimento das mudas, já suas mais elevadas porosidades permitiram maior movimentação de água e ar em suas estruturas, favorecendo a indução, a diferenciação e o crescimento de raízes.

Maiores valores da relação H/MSPA indicam menor resistência das mudas aos estresses ambientais, após o transplantio para o campo. Analisando-se a Figura 1f, observa-se que as mudas crescidas nos substratos Bioplant ${ }^{\circledR}$ e 75B+25BC apresentaram os menores valores da relação (1,029 e 0,875 respectivamente). Segundo Gomes (2001), quanto menor o quociente obtido, maior será a capacidade de sobrevivência, resultado de maior rusticidade das mudas.

Os maiores Índices de Qualidade de Dickson (IQD), observados nas plantas crescidas nos substratos Bioplant $^{\circledR}(0,28), 75 \mathrm{~B}+25 \mathrm{BC}(0,26)$ e $50 \mathrm{~B}+50 \mathrm{BC}(0,25)(\mathrm{Fi}-$ gura $1 \mathrm{~g}$ ), foram superiores ao valor mínimo de 0,20 (Hunt, 1990, citado por Gomes, 2001), recomendado para que a variável seja um bom indicador de qualidade de mudas. Nota-se que, além da inferioridade estatística apresentada pelos tratamentos 25B+75BC $(0,17)$ e Bagaço de Cana
$(0,09)$ (Figura 1g), esses não alcançaram o valor de 0,20 para o IQD.

Gomes (2001), citando trabalhos de outros pesquisadores, afirmou que, quanto maior o valor do IQD e menor o valor da relação H/PMSPA, melhor será a qualidade da muda produzida; em vista disso, os substratos Bioplant ${ }^{\circledR}$, $75 \mathrm{~B}+25 \mathrm{BC}$ e $50 \mathrm{~B}+50 \mathrm{BC}$ foram os mais indicados para a produção de canafístula.

As variáveis taxa de crescimento absoluto (TCA) e taxa de crescimento relativo (TCR) podem ser usadas para estimar a velocidade média de crescimento, ao longo do período de observação, e a rapidez com que uma planta cresce, quando comparado o tamanho final com seu tamanho inicial, respectivamente (Benincasa, 2003). Para as duas variáveis, os substratos Bioplant ${ }^{\circledR}, 75 \mathrm{~B}+25 \mathrm{BC}$ e 50B+50BC mostraram-se mais eficientes (Figuras 1h e 1i). Esse resultado pode estar atribuído ao porte das mudas crescidas nesses substratos, que apresentaram maior produção de matéria seca (Figura 1e), reflexo de suas características químicas e físicas superiores (Tabela 1). Maiores taxas de crescimento de mudas, utilizando-se, na composição dos substratos, resíduos orgânicos, também foram observados por Dantas et al. (2009).
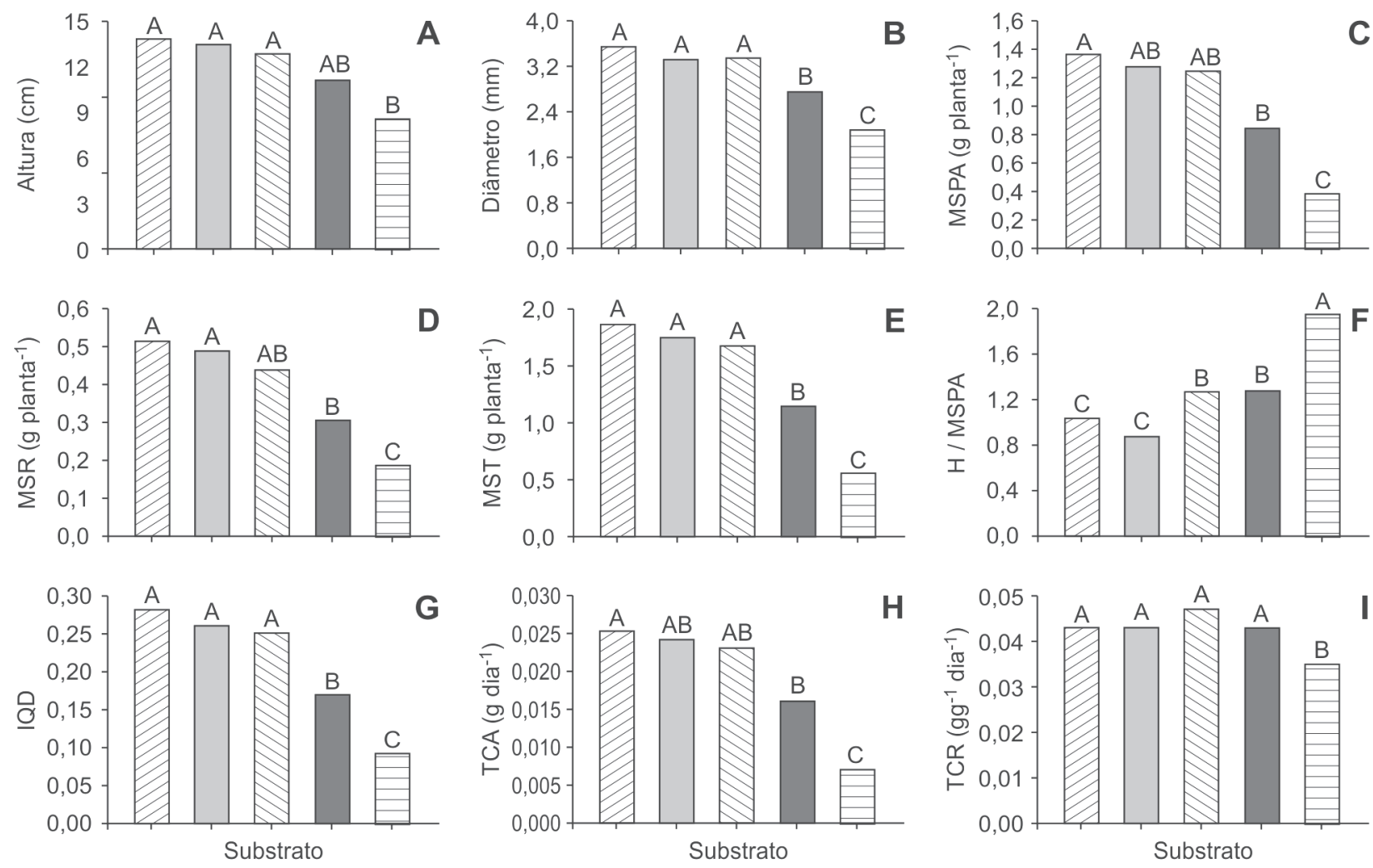

$$
\text { Bioplant }^{\circledR} \quad \square 75 \mathrm{~B}+25 \mathrm{BC}
$$

$\triangle 50 \mathrm{~B}+50 \mathrm{BC}$

$25 B+75 B C$

Bagaço de Cana

Figura 1. Altura da parte aérea; diâmetro do coleto; massa seca da parte aérea (MSPA) raiz (MSR) e total (MST); relação altura da parte aérea e massa seca da parte aérea (H/MSPA); índice de qualidade de Dickson (IQD); taxa de crescimento absoluto (TCA) e taxa de crescimento relativo (TCR) de mudas de canafístula (Peltophorum dubium) cultivadas em cinco tipos de substratos. Médias seguidas de mesma letra não diferem entre si, pelo teste Tukey a 5\% de probabilidade. 


\section{CONCLUSÕES}

A dormência tegumentar das sementes de canafístula foi superada, de forma mais eficiente, pelos tratamentos de imersão em água quente e de escarificação com ácido sulfúrico, sendo eles responsáveis por proporcionarem menor tempo de emergência das plântulas, o que possibilitou a formação de mudas com qualidade, em menor tempo.

O uso do bagaço de cana na composição de substratos, a partir da mistura com o Bioplant ${ }^{\circledR}$, mostrou-se técnica e economicamente viável, na proporção de 3:1 (75\% de Bioplant $+25 \%$ de Bagaço de cana) e 1:1 (50\% de Bioplant $+50 \%$ de Bagaço de cana), nas quais proporcionaram as maiores taxas de crescimento e maiores índices de qualidade das mudas de canafístula.

\section{REFERÊNCIAS}

Alves EU, Guedes RS, Gonçalves EP, Viana JS, Santos SS \& Moura MF de (2011) Effect of temperature and substrate on germination of Peltophorum dubium (Sprengel) Taubert seeds. Acta Scientiarum. Biological Sciences, 33:113-118.

Azeredo GA, Paula RC, Valeri SV \& Moro FL (2010) Superação de dormência de sementes de (Piptadenia moniliformis Benth). Revista Brasileira de Sementes, 32:49-58.

Benincasa MMP (2003) Análise de crescimento de plantas: noções básicas. Jaboticabal, FUNEP. 41p.

Brancalion PHS, Mondo VHV \& Novembre ADLC (2011) Escarificação química para a superação da dormência de sementes de saguaraji-vermelho (Colubrina glandulosa Perk. Rhamnaceae). Revista Árvore, 35:119-124.

Carvalho RIN \& Carvalho DB (2009) Germinação de sementes de um ecótipo de paspalum da região de Guarapuava -PR. Semina: Ciências Agrárias, 30:1187-1194.

Cunha AO, Andrade LA, Bruno RLA, Silva JAL \& Souza VC (2005) Efeitos de substratos e das dimensões dos recipientes na qualidade das mudas de Tabebuia impetiginosa (Mart. Ex D.C.) Standl. Revista Árvore, 29:507-516.

Dantas BF, Lopes AP, Silva FFS, Lúcio AA, Batista PF, Pires MMML \& Aragão CA (2009) Taxas de crescimento de mudas de catingueira submetidas a diferentes substratos e sombreamentos. Revista Árvore, 33:413-423.

Dickson A, Leaf AL \& Hosner JF (1960) Quality appraisal of white spruce and white pine seedling stock in nurseries. Forestry Chronicle, 36:10-13.

Dutra TR, Massad MD \& Santana RC (2012) Parâmetros fisiológicos de mudas de copaíba sob diferentes substratos e condições de sombreamento. Ciência Rural, 42:1212-1218.

Freitas TAS, Barroso DG, Carneiro JGA, Penchel RM \& Figueiredo FAMM (2006) Mudas de eucalipto produzidas a partir de miniestacas em diferentes recipientes e substratos. Revista Árvore, 30:519-528.

Gomes JM (2001) Parâmetros morfológicos na avaliação da qualidade de mudas de Eucalyptus grandis, produzidas em diferentes tamanhos de tubete e de dosagens de N-P-K. Tese de Doutorado. Universidade Federal de Viçosa, Viçosa. 126p.

Gomes JM, Couto L, Leite HG, Xavier A \& Garcia SLR (2002) Parâmetros morfológicos na avaliação da qualidade de mudas de Eucalyptus grandis. Revista Árvore, 26:655-664.
Gomes JM, Couto L, Leite HG, Xavier A \& Garcia SLR (2003) Crescimento de mudas de Eucalyptus grandis em diferentes tamanhos de tubetes e fertilização N-P-K. Revista Árvore, 27:113-127

Hunt R (1982) Plant growth curves: The functional approach to plant growth analysis. London, Edward Arnold. 247p.

Lorenzi H (2002) Árvores brasileiras: manual de identificação e cultivo de plantas arbóreas nativas do Brasil. Nova Odessa, Plantarum. 368p.

Martins CC, Machado CG \& Nakagawa J (2008) Temperatura e substrato para o teste de germinação de sementes de barbatimão ((Stryphnodendron adstringens (Mart.) Coville (Leguminosae)). Revista Árvore, 32:633-639.

Muniz MFB, Silva LM \& Blume E (2007) Influência da assepsia e do substrato na qualidade de sementes e mudas de espécies florestais. Revista Brasileira de Sementes, 29:140-146.

Oliveira AB \& Medeiros Filho S (2007) Influência de tratamentos pré-germinativos, temperatura e luminosidade na germinação de sementes de leucena, cv. Cunningham. Revista Brasileira de Ciências Agrárias, 2:268-274.

Oliveira LM, Davide AC \& Carvalho MLM (2003) Avaliação de Métodos para Quebra de Dormência e para Desinfestação de Sementes de Canafístula (Peltophorum dubium (Sprengel) Taubert. Revista Árvore, 27:597-603.

Pacheco MV \& Matos VP (2009) Método para superação de dormência tegumentar em sementes de Apeiba tibourbou Aubl. Revista Brasileira de Ciências Agrárias, 4:62-66.

Piroli EL, Custódio CC, Rocha MRV \& Udenal JL (2005) Germinação de sementes de canafístula Peltophorum dubium (Spreng.) Taub. tratadas para superação da dormência. Colloquium Agrariae, 1:13-18.

Salerno AR, Shallengerger TCH \& Stuker H (1996) Quebra de dormência em sementes de canafístula. Agropecuária Catarinense, 9:09-11.

Scalon SPQ, Mussury RM, Wathier F, Gomes AA, Silva KA, Pierezan L \& Scalon Filho H (2005) Armazenamento, germinação de sementes e crescimento inicial de mudas de Enterolobium contortisiliquum (Vell.) Morong. Acta Scientiarum. Biological, 27:107-112.

Serrano LAL, Marinho CS, Carvalho AJC \& Monnerat PH (2004) Efeito de sistemas de produção e doses de adubo de liberação lenta no estado nutricional de porta-enxerto cítrico. Revista Brasileira de Fruticultura, 26:524-528.

Serrano LAL, Silva CMM, Ogliari J, Carvalho AJC, Marinho CS \& Detmann E (2006) Utilização de substrato composto por resíduos da agroindústria canavieira para produção de mudas de maracujazeiro-amarelo. Revista Brasileira de Fruticultura, 28:487-491.

Simões D, Silva RBG \& Silva MR (2012) Composição do substrato sobre o desenvolvimento, qualidade e custo de produção de mudas de Eucalyptus grandis Hill ex Maiden $\times$ Eucalyptus urophylla S. T. Blake. Ciência Florestal, 22:91-100.

Souza CAM, Oliveira RB, Martins Filho S \& Lima JSS (2006) Crescimento em campo de espécies florestais em diferentes condições de adubações. Ciência Florestal, 16:243-249.

Statsoft Inc. (2007) STATISTICA - Data analysis software system. Version 8.0. Disponível em: 〈www.statsoft.com>. Acessado em: 12 de março 2010.

Vasconcelos JM, Cardoso TV, Sales JF, Silva FG, Vasconcelos Filho SC \& Santana JG (2010) Métodos de superação de dormência em sementes de croada (Mouriri elliptica Mart). Ciência e Agrotecnologia, 34:1199-1204. 